\title{
Perineural Migration of Stem Cells in the Model of Damaged Heart Nodes
}

\author{
Kulchitsky Vladimir*1, Zamaro Alexandra ${ }^{1}$ and Koulchitsky Stanislav ${ }^{2}$ \\ ${ }^{1}$ Institute of Physiology, National Academy of Sciences, Minsk, Belarus \\ ${ }^{2}$ Liege University, Liege, Belgium
}

*Corresponding author: Kulchitsky Vladimir, Institute of Physiology, National Academy of Sciences, Belarus

\section{ARTICLE INFO}

Received: 慧 February 08, 2019

Published: 㗀 February 14, 2019

Citation: Kulchitsky Vladimir, Zamaro Alexandra, Koulchitsky Stanislav. Perineural Migration of Stem Cells in the Model of Damaged Heart Nodes. Biomed J Sci \& Tech Res 14(4)-2019. BJSTR. MS.ID.002578.

\begin{abstract}
Unilateral vagotomy $(n=15)$ with simultaneous injection of 10 thousand stem cells in $10 \mu \mathrm{l}$ of culture medium to intact vagus nerve $(\mathrm{n}=9)$ was performed on Wistar rats anesthetized with ketamine-xylazine-acepromazine. Migration of stem cells to atriums and ventricles was tracked by fluorescent markers. Also protective role of perineural injection of stem cells was established in relation to development of destructive processes in heart ganglions. Unilateral vagotomy and injection of stem cells to intact vagus nerve resulted in preservation of cell structure in sinoatrial ganglion and recovery of cardiac rhythm. It was assumed that technique of perineural migration of stem cells along vagus nerve fibers to heart is promising for prevention of arrhythmias and heart failure development in patients with impaired heart function.
\end{abstract}

Abbreviations: $\mu \mathrm{m}$ : Micrometer; SCs: Stem cells

\section{Introduction}

Issues related to arrhythmias and heart failure development still remain unresolved and socially important in all countries. This is confirmed by statistical data on high risk of mortality due to cardiovascular pathology [1,2]. Considering scientific literature [1,2], authors paid attention to reasonability of stem cells (SCs) use as additional therapy in heart diseases. Authors experimentally substantiated technology [3] based on the use of SC perineural migration along vagus nerve fibers to heart [3]. The fact of perineural migration of SC to damaged heart areas was experimentally proved on rats [3]. Destructive events in heart atriums and ventricles are caused by the process of degeneration of vagus and sympathetic nerve fibers. These neurodegenerative processes developed after transection of vagosympathetic trunk at cervical level in experiments on laboratory animals (Figure 1). Initiation of experimental destruction in heart [3] was required to test hypothesis on the ability of SCs to move along vagus nerve namely to damaged heart regions. Similar SCs ability was previously demonstrated in relation to brain [4-9]. It is known that SCs are necessary for reparation of damaged tissues. Recovery of cell and tissue structure with SCs is accompanied with normalization of functional activity of cells, organs and tissues.

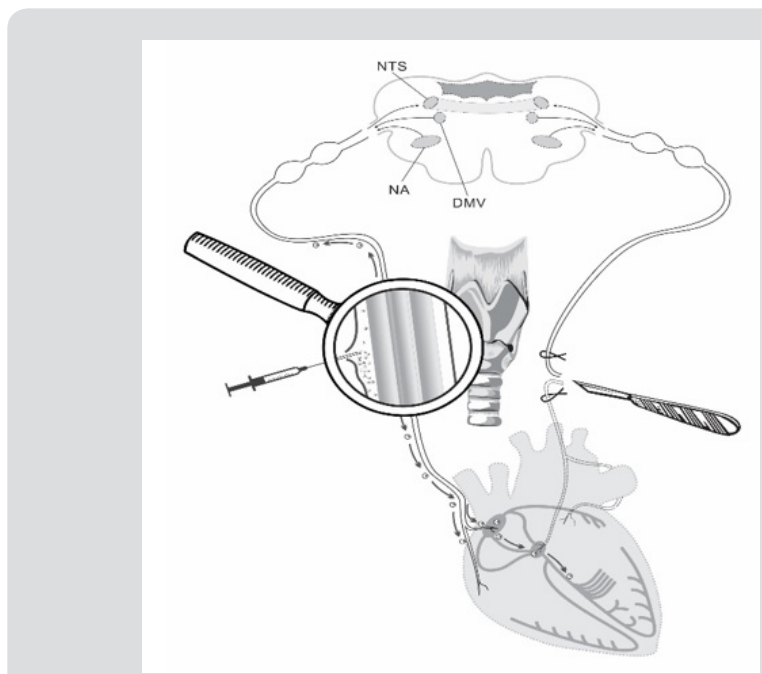

Figure 1: Scheme of unilateral vagotomy and perineural implantation of stem cells. Explained in text. 
The mechanism of SCs migration to damaged areas is initiated by plenty of trophic factors and other signaling molecules appearing there. Unilateral vagotomy was chosen among various destruction models to minimize heart injuries (Figure 1). It was decided to inject SCs into perineural space of intact vagus nerve on the other side to exclude influence of neurotrophic factors on migration process. We supposed that SCs will start moving along vagus nerve fibers directly to those signaling molecules which will appear in the areas of degenerated vagus nerve fibers after its transection (Figure 1). Such destructive processes in heart are associated with the ones in real life which develop in patients with infarction, syncope events, vasovagal conditions and various arrythmias. Authors are interested, it is really and safely to use minimally invasive approach to inject SCs into perineural space of vagus nerve to activate reparative processes in automaticity nodes and those destructed heart regions which usually initiate development of cardiac arrhythmias and heart failure in patients. Authors understand that such technique of SCs perineural migration to heart could be implemented and used in complex classic therapy after approval by physicians.

\section{Vagus Nerve as One of the Ways of Stem Cells Delivery to Heart}

Establishment of fact of SCs perineural migration to heart [3] was a kind of departure point to conduct series of experiments to reveal features of structural changes in heart which are the trigger for initiation of SCs migration processes to damaged tissue regions. 4 adult male Wistar rats weighing 190-220g at the time of the experiments have been chosen. Vagotomy (4 rats) was performed under ketamine-xylazine-acepromazine anesthesia (55.6, 6.6 and $1.1 \mathrm{mg} / \mathrm{kg}$, respectively, i/p). Unilateral (left side) vagotomy was performed in all four rats at the cervical level of neck (Figure 1). Two rats of four received 10 thousand SCs in $10 \mu \mathrm{l}$ culture medium in perineural space of vagus nerve after vagotomy (Figure 1). SCs were marked with monoclonal antibodies to CD90 and PKH67 Green Fluorescent Cell Linker.

Rats were decapitated in one week after vagotomy and horizontal serial heart slices $8 \mu \mathrm{m}$ in thickness were prepared using Microm HM525 (Germany) cryostat. SCs distribution was visualized using Zeiss AxioVert 200M fluorescence microscope with Zeiss AxioCam HRm CCD camera. Ten serial heart slices were taken with the interval of $50 \mu \mathrm{m}$, were stained in hematoxylin-eosin and structural changes were visualized using Fluorescent microscope MPV-2 (Leitz, Germany) with camera Leica DC 300F (Germany).

Figure 2 shows distribution of PKH67 Green Fluorescent Cell Linker labeled SCs in the area of left ventricle. SCs revealed in destructed region of heart ventricle in one week after injection into perineural space of vagus nerve prove that they moved there from the place of injection. Literature data on the vast innervation of heart ventricles by vagus nerve [10-18] confirms this point of view.

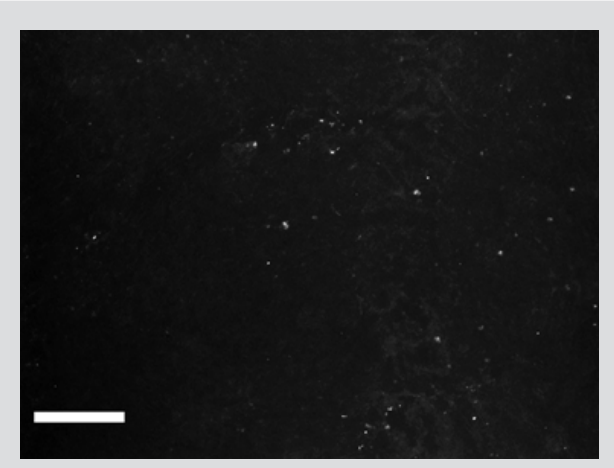

Figure 2: Distribution of PKH67-labeled SCs in the left ventricular heart of rat. Bar - $100 \mu \mathrm{m}$. Explained in text.

By the way, we established earlier that implanted SCs appear in sinoatrial heart node within the first day after vagus transection [3]. Figure 3A shows destruction foci in sinoatrial node in right atrium in rat in one week after vagus nerve transection. Figure $3 \mathrm{~B}$ shows different picture: cells of sinoatrial node are visualized in right atrium of rat in one week after vagus nerve transection and perineural injection of SCs in intact vagus nerve. There were no signs of destruction noted in sinoatrial node in this case. Therefore, SCs migration along vagus nerve fibers to heart tissue is the basis for realization of reparative potential of SCs in the area of main pacemaker and such obvious way of SCs delivery to heart appears to be promising method of correction of structural and functional state of heart nodes and myocytes.

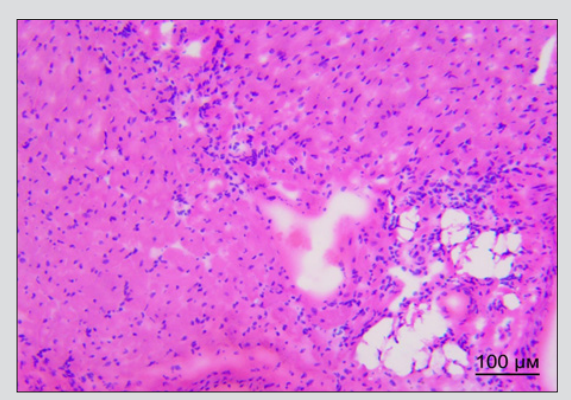

Figure 3A: Structural features of the rat sinoatrial ganglion: $3 \mathrm{~A}$ - Destroyed areas in the sinoatrial ganglion in the right atrium of the rat.

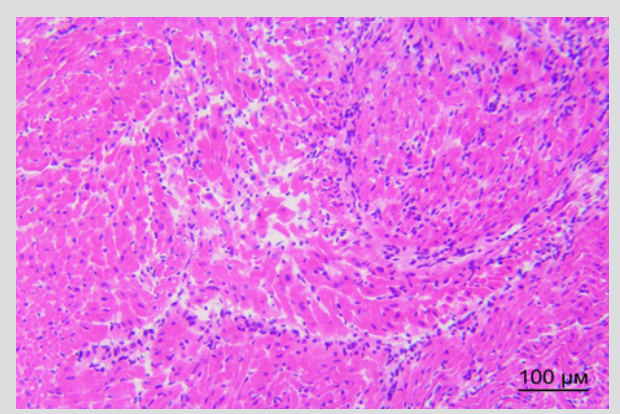

Figure 3B: There are no signs of damage in the sinoatrial node in the right atrium of the rat. Bar - $100 \mu \mathrm{m}$. Explained in text. 


\section{Characteristics of Cardiac Activity After Unilateral Vag- otomy at Cervical Level}

Separate series of experiments was performed on 11 Wistar rats weighing 190-220g at the time of the experiments. Heart rate was analyzed with non-invasive pulse recorder L120E INSELT (USA) before unilateral vagotomy on different sides and repeatedly after vagotomy. Surgical procedures were performed as described above. Four animals were subjected to unilateral vagotomy alone. Seven animals received vagotomy together with simultaneous injection of SCs into intact vagus nerve. All the rats showed heart rate changes and intermittent arrhythmia regardless the side of manipulation in one day after unilateral vagotomy: bradycardia in 7 rats, tachycardia in 4 rats. Heart rate was not recovered in those rats who didn't receive SCs injection even in one week after vagotomy; arrhythmia worsened in one rat. Heart rate recovered in all rats received SCs injection together with unilateral vagotomy.

\section{Conclusion}

Protective role of perineural SCs injection in relation to destructive processes development in heart nodes was demonstrated in experiments on Wistar rats using unilateral vagotomy technique. Preservation of sinoatrial node cells structure and recovery of cardiac rhythm was established after unilateral vagotomy and injection of SCs into intact vagus nerve. Therefore, method of SCs perineural migration along vagus nerve fibers to heart seems promising for prevention of arrhythmias and heart failure development in patients with impaired cardiac function of organic origin.

\section{Acknowledgement}

This pooled analysis was funded by 000 "Synergy", and by innovative fund of Brest Regional Executive Committee (2017-2019), and by BRFFI B18P-227.

\section{References}

1. Graham GN, Jones PG, Chan PS, Arnold SV, Krumholz HM, et al. (2018) Racial Disparities in Patient Characteristics and Survival After Acute Myocardial Infarction. JAMA Netw Open 1(7): e184240.

2. Thiruganasambandamoorthy V, Stiell IG, Sivilotti MLA, Rowe BH, Mukarram M, et al. (2017) Predicting Short-term Risk of Arrhythmia among Patients with Syncope: The Canadian Syncope Arrhythmia Risk Score. Acad Emerg Med 24(11): 1315-1326.

3. Zamaro A, Koulchitsky S, Pashkevich S, Stukach Y, Dosina M, et al. (2019) Perineural Way of Stem Cells Migration to Injured Heart Regions. Biomed J Sci \& Tech Res 14 (1): 1-4.

\section{ISSN: 2574-1241}

\section{DOI: 10.26717.BJSTR.2019.14.002578}

Kulchitsky Vladimir. Biomed J Sci \& Tech Res

This work is licensed under Creative Commons Attribution 4.0 License

Submission Link: https://biomedres.us/submit-manuscript.php
4. Kulchitsky V, Zamaro A, Shanko Y, Koulchitsky S (2018) Prospects of Perineural Implantation of Stem Cells in Recovery of Neural Networks' Functions in Brain Diseases. Biomed J Sci\&Tech Res 10(3): 1-4.

5. Shanko Y, Zamaro A, Takalchik-Stukach Y, Koulchitsky S, Pashkevich S, et al. (2018) Mechanisms of Neural Network Structures Recovery in Brain Trauma. Biomed J Sci\&Tech Res 7(5): 1-2.

6. Shanko Y, Navitskaya V, Zamaro A, Krivenko S, Zafranskaya M, et al. (2018) Prospects of Perineural Administration of Autologous Mesenchymal Stem Cells of Adipose Tissue in Patients with Cerebral Infarction. Biomed J Sci\&Tech Res 10(1): 1-3.

7. Shanko Y, Navitskaya V, Zamaro A, Zafranskaya M, Krivenko S, et al. (2018) Somatotopic principle of perineural implantation of stem cells in patients with brain injuries. J Neurol Stroke 8(5): 259-261.

8. Kulchitsky V, Zamaro A, Pashkevich S, Sushko T, Koulchitsky S (2018) Nasolacrimal way of stem cells implantation. J Neurol Stroke 8(2): 110111.

9. Kulchitsky V, Zamaro A, Shanko Y, Koulchitsky S (2018) Positive and negative aspects of cell technologies in cerebral diseases. J Neurol Stroke 8(2): 87-88.

10. Kapa S, DeSimone CV, Asirvatham SJ (2016) Innervation of the heart: An invisible grid within a black box. Trends Cardiovasc Med 26(3): 245-257.

11. Longhurst JC, Tjen-A-Looi SC, Fu LW (2001) Cardiac sympathetic afferent activation provoked by myocardial ischemia and reperfusion. Mechanisms and reflexes. Ann N Y Acad Sci 940: 74-95.

12. Han S, Kobayashi K, Joung B, Piccirillo G, Maruyama M, et al. (2012) Electroanatomic remodeling of the left stellate ganglion after myocardial infarction. J Am Coll Cardiol 59(10): 954-961.

13. Hasan W (2013) Autonomic cardiac innervation: Development and adult plasticity. Organogenesis 9(3): 176-193.

14. Noheria A, Patel SM, Mirzoyev S, Madhavan M, Friedman PA, et al. (2013) Decreased postoperative atrial fibrilla-tion following cardiac transplantation: The significance of autonomic denervation. Pacing Clin Electrophysiol 36(6): 741-747.

15. Shen MJ, Zipes DP (2014) Role of the autonomic nervous system in modulating cardiac arrhythmias. Circ Res 114(6): 1004-1021.

16. De Ferrari GM, Crijns HJ, Borggrefe M, Milasinovic G, Smid J, et al. (2011) Chronic vagus nerve stimulation: A new and promising therapeutic approach for chronic heart failure. Eur Heart J 32(7): 847-855.

17. Wang Z, Yu L, Chen M, Wang S, Jiang H (2014) Transcutaneous electrical stimulation of auricular branch of vagus nerve: A noninvasive therapeutic approach for post-ischemic heart failure. Int J Cardiol 177(2): 676-677.

18. Florea VG, Cohn JN (2014) The autonomic nervous system and heart failure. Circ Res 114(11): 1815-1826.

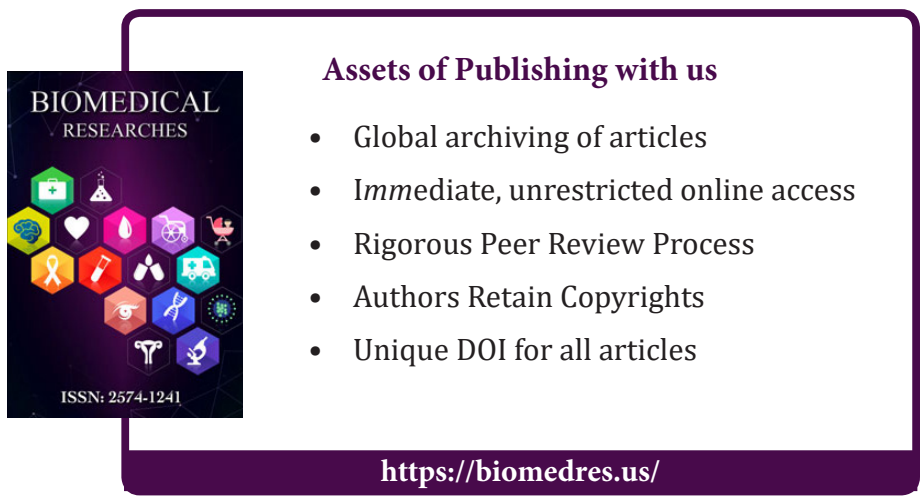

Copyright@ Kulchitsky Vladimir| Biomed J Sci \& Tech Res| BJSTR. MS.ID.002578. 